\title{
NURSING PROFESSION WITH HIGH-END CHALLENGES IN INDIA
}

\author{
Naveen .H. Simon ${ }^{1}$, Abhishek .S.Lachyan ${ }^{2} \&$ Shivani Sharma ${ }^{3}$
}

Director, School of Nursing and Health Sciences, Noida International University, Delhi NCR.' Assistant Professor, School of Health Sciences, Department of Public Health, Noida International University, Delhi NCR. ${ }^{2}$ Assistant Professor, School of Nursing and Health Sciences, Noida International University, Delhi NCR 3

\section{Email id :dir.son@niu.edu.in}

In this $21^{\text {st }}$ century, the nursing professions are one noble job that provides the advanced wellbeing and health care facilities to the patients, clients, families and communities. A nurse helps in bringing a new life into the world. Concurrently, major issues have occurred even as she cares tirelessly for the sick and the injured. While emphasizing on community based care for prevention of illness and treats health conditions. They give holistic care that is developmentally, psychosocially as well as spiritual needs of the patients. Despite their tremendous work and dedication, still they have to face numerous challenges in their work place. 
There are several issues identified but not limited to

\section{Violence at Workplace}

Violence is wide spreading in the health care sector. There is a lot of work load and heavy responsibility on the shoulders of staff nurses which leads to disturbance in their mental peace. In health care settings the sources of violence can be through the patients, visitors and even through the coworkers. According to the Indian census 2011 it was found that 80 percent of violent cases were caused by the patients and their relatives. Work over load due to shortage of staff sometimes lead to unmanageable patient work- load. The ratio between patient and nurses is to be maintained as it eventually affects the health care delivery system. Due to less number of nurses, they are unable to take better care of the patients. Due to which the patients and their relatives suffer and or even die. The short staffing pattern in hospitals, settings cannot be overlooked as it leads to double shift of nurses and long working hours which adversely affects the health of the nurses and which finally affects the efficient nursing care provided to the patients.

\section{The Risk of Occupational Health Problems}

Several authors not limited to Ramsay, D James have reported Nurses as having higher risk of getting health hazards due to rate of exposure if they do not take proper precaution during patient care. Lack of coordination among nurse's team in the hospitals and blamed for any mishap. The non-availability of the necessary equipment's in the hospital, lack of recognition or appreciation and wages. More also nurses were never allowed to work independently as a nurse practitioner. Which are over- looked in organizations, leads to several health disorders among the nursing fraternity and goes unreported. 